\title{
VARIATIONS IN SOLAR RADIATION AND THE CAUSE OF ICE AGES
}

\author{
By F. Hoyle and R. A. Lyttheton \\ (St. John's College, Cambridge)
}

\begin{abstract}
Most astronomical hypotheses on the causes of ice ages are dynamically untenable. Alterations in the amount of solar radiation, however, have long been recognized as a possible cause, but only with recent progress in the theory of stellar evolution has it become clear that such changes must occur. At irregular intervals the sun will pass, and will have passed, with low relative speeds through interstellar hydrogen clouds, and the gravitational action of the sun leads to an increase in the quantity of material falling to the surface with high velocity. The conversion of the kinetic energy of fall of this material results in an increase of emission at the solar surface. Increases of order up to about ro per cent of the present total radiation could occur, and the process is such that the extra energy would be located mainly in the shorter wave-lengths.
\end{abstract}

ZuSAmmRnfassung. Die meisten astronomischen Hypothesen über die Ursachen der Eiszeiten sind dynamisch unhaltbar. Änderungen im Ausmass der Sonnenstrahlungen sind indessen seit langem als eine mögliche Ursache anerkannt, jedoch erst durch den jüngsten Fortschritt in der Theorie der Entwicklung der Sterne ist es klar geworden, dass solche Änderungen stattfinden müssen. Die Sonne wird sich in unregelmässigen $Z$ wischenräumen mit geringer relativer Geschwindigkeit durch die sich zwischen den Sternen befindlichen Wasserstoff Wolken bewegen und bewegt haben, und die Gravitationskraft der Sonne führt dazu, dass die Quantität an Material, die mit grosser Geschwindigkeit auf die Oberfläche fällt, zunimmt. Die Umsetzung der kinetischen Energie dieses fallenden Materials führt zu einer erhöhten Ausstrahlung an der Sonnenoberfläche. Diese Zunahme an Ausstrahlung könnte sich bis auf circa 10\% der gegenwärtigen Totalstrahlung belaufen, und der Prozess verläuft so, dass die Extraenergie sich hauptsächlich in den kürzeren Wellenlängen befinden würde.

HyPothesEs on the causes of the ice ages are of two kinds. There are those of a purely terrestrial character, such as alterations in the carbon dioxide or dust content of the atmosphere (supposedly due to volcanic activity), which assume that the Earth is always in receipt of the same solar radiation. They ascribe the variations in climate to the changed physical conditions at the Earth altering the effect of this radiation. There are also hypotheses of external influence, such as changes in the Earth's orbit or inclination of its rotation axis, which initiate changed conditions at the Earth and bring changes of climate in their train.

Now most hypotheses so far proposed under these two heads have been of a somewhat ad hoc character and seem to be aimed purely at a direct explanation of the ice ages. They do not appear to have existed beforehand as a factor demanding consideration but have more or less had to be sought out and forced into the discussion. Where purely dynamical hypotheses are concerned it has been shown with certainty that the necessary changes would not occur with the required irregularity or to an extent having important influence on climate. On the other hand it had long been recognized that by far the most obvious and direct cause of climatic variation would be changes in solar radiation were there any real basis for supposing such to happen. But up till 1939 the whole theory of the structure of stars, which was understood beyond the possibility of serious revision of ideas, not only gave no indication of even the smallest irregular changes in the sun's radiation rate but went so far as to appear to rule them out altogether. In contrast however to the confidence felt in the theory of stellar constitution, the very progress that had brought it about had successively demolished existing descriptive accounts and provisional theories of stellar evolution. Thus although astronomers fully understood the source of stellar energy and the mechanism of its transmission through the star they were without any clear ideas of the origin of the stars and their evolution.

It would take too much space to explain in detail the nature of the difficulties, but the solution was close at hand all the time and lay in the recognition that the hydrogen of the stars, whose transmutation is the ultimate source of their energy, must in some way be replenished from without. Indeed the very existence of the stars, particularly the very bright and massive ones, is in reality 
enough to prove that a process of replenishment must be permanently available. But there is in addition a vast amount of circumstantial evidence from almost every branch of theoretical astronomy. The existence of interstellar matter was already well known, but for various reasons hydrogen does not reveal its presence (mass for mass) as plainly as do many other elements, such as calcium and sodium, which in fact occur to a far less extent in interstellar space. Observational studies during the past decade or so have, however, led to increased estimates of the quantity of atomic hydrogen at fairly high temperatures $\left(\sim 10,000^{\circ}\right)$. The existence of molecular hydrogen at low temperatures is also likely but would be difficult to prove by direct observation. The observed material occurs in the form of irregularly distributed clouds of greatly varying sizes which, according to recent estimates, occupy something like 5 per cent of interstellar space. Their linear dimensions attain to values of order $10^{19}$ or sometimes $10^{20} \mathrm{~cm}$. for the largest, but their sizes and forms are extremely irregular. The densities of ionized hydrogen inferred for some of them are of order ${ }_{10}-22 \mathrm{gm}$. per $\mathrm{cm} .^{3}$, but there has been considerable reluctance on the part of astronomers to admit high values for the density, so that it may well be that even these values, which already exceed by a factor of Ioo the maximum considered possible ten years ago, are still on the low side.

It accordingly becomes a self-presented problem of astronomy to determine what would happen to a star, in particular the sun, if it should happen in its motion round the galaxy to encounter and pass through such a cloud. Now the clouds must necessarily take part with the stars in the general rotatory motion of the galaxy, but superposed on this they will also have their own independent small random motions as do the stars. The galactic rotation involves velocities measured in hundreds of kilometres per second, whereas the random speeds are of the order of ro $\mathrm{km}$. $/ \mathrm{sec}$. It turns out that an encounter with a cloud is the more effective in changing the energy output of the star the smaller the relative speed of the encounter. Ordinary relative velocities may average something like Io or $20 \mathrm{~km}$. $/ \mathrm{sec}$., but encounters at lower speeds, $\sim 2 \mathrm{~km}$./sec. or less, will have quite appreciable probability of occurring. The time taken by the sun to travel $10^{19} \mathrm{~cm}$. at $2 \mathrm{~km}$. $/ \mathrm{sec}^{-1}$ is about two million years, but as the dimensions of a cloud might be far less than this, and the speed different, much shorter times of passage are just as possible. Also, the density in any one cloud might vary. It is seen therefore that the intervals predicted by the theory are necessarily irregular and are of the kind long since known to be characteristic of the intervals of glaciation.

It has now to be explained how the passage through a cloud may bring about a change in the solar radiation. At a density of order $\mathrm{ro}^{-22} \mathrm{gm} . / \mathrm{cm} .{ }^{3}$ the whole amount per square centimetre across the line of sight between the sun and Earth (a distance of $1.5 \times 10^{13} \mathrm{~cm}$.) would be less than $10^{-7} \mathrm{gm}$. even allowing for concentration towards the sun, and there is no possibility of any appreciable effect of obscuration of the sun's light. What actually happens is an increase in the sun's rate of emission caused ultimately by the gravitational field of the sun, which draws in the cloud and results in all material being captured that passes within a distance of about $2 G M / v^{2}(G=$ constant of gravitation, $M=$ mass of the sun, $v=$ relative velocity of the cloud when at great distance from the sun). For a moderate value of $v$ this "capture radius" extends far beyond the Earth's orbit to a distance greater than that of any of the planets. The quantity of material captured by the sun per unit time can be shown to be about $2 \cdot 5 G^{2} M^{2} \rho / v^{3}$, where $\rho$ is the density in the cloud. Now all this material eventually falls into the sun and arrives at the surface with a speed of the same order as the velocity of escape from the solar surface-rather more than $600 \mathrm{~km}$. $/ \mathrm{sec}$. The kinetic energy acquired by the material in falling to the sun will at impact be converted into thermal and radiant energy, and once a steady state has been reached an increase in the solar luminosity by just this amount will be maintained. For a density of $10^{-21} \mathrm{gm} . / \mathrm{cm} .^{3}$ the total energy supply is readily found to be about $3 \times 10^{32} / v^{3}$ ergs per second, which is about ro per cent of the ordinary solar luminosity if $v=\mathrm{r} \mathrm{km}$./sec. This figure may probably be considered as an estimate of the largest increase likely to occur, though we cannot be sure of this, because, as far as the theory is concerned, there is no upper limit owing to the factor $v^{-3}$ in the formula. 
A highly important feature of the process has been established by an examination of the precise mechanism by which the accreted hydrogen is absorbed into the outer layers of the sun. This shows that most of the kinetic energy brought to the sun is re-emitted in the form of ultra-violet radiation, so that even in encounters in which only a one per cent change of total luminosity occurred, the increase would nearly all be in the ultra-violet region of the spectrum. This would represent a manifold increase in this range of wave-length over the normal amount (which at the present time is largely contributed by this same process taking place at a much more moderate rate than envisaged for the ice age periods).

This source of variation in both the quality and quantity of the solar radiation as a possible hypothesis for explaining the ice ages first presented itself as a result of indirect arguments involving questions of stellar evolution. At that time no observational evidence of a clear-cut nature was available on many of the factors concerned, for otherwise the ideas might well have been arrived at before. But considerable evidence on many aspects of the accretion process has accumulated since, all of which there is not space to examine here. The simplest example is provided by direct observations that have recently been made of certain dwarf stars whose spectra show anomalous hydrogen emission lines of far greater strength than would usually be associated with their prevailing low surface temperatures. The presence of these lines demands an excess emission in the ultra-violet approaching ro per cent of the luminosity of the star, and moreover the stars concerned are seen to lie in dense regions of interstellar gas.

It may thus be concluded that there is now incontrovertible astronomical evidence of both a theoretical and an observational kind showing that the radiation reaching the Earth from the sun will in the past have been subject to irregularities of increase of the type described above. What the exact consequences of these will be in regard to terrestrial climate is not of course the province of theoretical astronomy, but the probability is strong that an adequate first cause of the major climatic variations lies here.

\section{O R R E S P N D E N C E}

The Editor,

The Fournal of Glaciology

Sir, Snow Conditions in the Lebanon

On II September 1949 considerable snow patches were visible on the northern slopes of the Lebanon mountains, some 18 miles $(29 \mathrm{~km}$.) south-east of Tripoli, the lowest snow being at $7700 \mathrm{ft}$. $(2347 \mathrm{~m}$.). Above this level there were patches on all the north faces. A crescent-shaped patch, some $280 \mathrm{yd}$. long and $50 \mathrm{yd}$. wide $(256 \times 45 \mathrm{~m}$.) was found between the twin peaks of Qornet es Saouda $\left(\mathrm{IO}, \mathrm{II}_{5} \mathrm{ft}\right.$., $3083 \mathrm{~m}$.). The northern edge of this patch terminated in a steep face estimated to be about $35 \mathrm{ft}$. (10.7 m.) deep. This snow bed was continuous, with a strip of snow at its eastern end which extended a further $500 \mathrm{yd} .(460 \mathrm{~m}$.) down the northern side of a gulley.

All the snow beds observed were well weathered by a series of crescent-shaped pits up to $8 \mathrm{ft}$. long, $3 \mathrm{ft}$. wide and $5 \mathrm{ft}$. deep $\left(2.5 \times \mathrm{I}_{5} \cdot 5 \times 0.9 \mathrm{~m}\right.$.). These lay close together in regular order, each running approximately north and south. They did not appear to be wind-formed.

During the $1948-49$ snow season the first snow fell in November and the last in May. Ski runs were possible down to about $6230 \mathrm{ft}$. (1900 m.).

P.O. Box 150 ,

Tripoli,

V. I. RusselL

The Lebanon

20 October 1949 